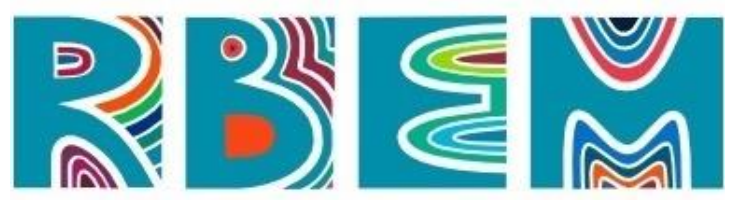

REVISTA BAIANA dE EDUCAÇÃo MATEMÁtica

\title{
ARTIGO
}

do] https://doi.org/10.47207/rbem.v2i01.10212

\section{Entendimento de professores que ensinam matemática sobre a relação entre jogo e raciocínio lógico}

\author{
SOUZA, Renaura Matos de \\ Prefeitura Municipal de São Desidério. Licenciatura em Matemática. ORCID: https://orcid.org/0000-0002-7897- \\ 269X . E-mail: renauramattos@gmail.com
}

SOUZA, Ilvanete dos Santos de

Universidade Federal da Bahia. Mestre em Ensino de Ciências e Matemática pela Universidade Federal de Sergipe. ORCID: https://orcid.org/0000-0001-6036-834X. E-mail: ilvanetess@ gmail.com

LIMA, Reinaldo Feio

Universidade Federal do Sul e Sudeste do Pará. Doutor em Educação pela Universidade Federal da Bahia. ORCID: https://orcid.org/0000-0003-2038-7997. E-mail: reinaldo.lima@ unifesspa.edu.br .

Resumo: Este estudo buscou respostas ao seguinte questionamento: como professores que ensinam matemática, nos Anos Finais do Ensino Fundamental, na rede municipal de Barreiras-BA, entendem os jogos matemáticos como instrumento de desenvolvimento do raciocínio lógico? Trata-se de uma pesquisa de abordagem qualitativa do tipo exploratória, que objetivou identificar e compreender o entendimento dos professores que ensinam matemática, nos Anos Finais do Ensino Fundamental, na rede municipal de Barreiras-BA, sobre os jogos matemáticos como instrumento de desenvolvimento do raciocínio lógico. Os dados foram produzidos por meio de um questionário exploratório, com questões abertas e fechadas e analisados à luz da Análise de Conteúdo de Bardin. A pesquisa evidenciou o reconhecimento pelos professores do uso do jogo enquanto recurso que auxilia o desenvolvimento do raciocínio lógico, mas alguns fatores influenciam o (não) uso do jogo enquanto recurso capaz de estimular o raciocínio lógico, destacando, ainda, as dificuldades conceituais como um "empecilho" para o avanço do raciocínio lógico. No entanto, esses profissionais sinalizam que fazem uso do jogo no contexto no qual atuam.

Palavras-chave: Entendimento do Professor. Matemática. Jogos. Raciocínio lógico.

\section{Understanding of teachers who teach mathematics about the relationship between game and logical reasoning}

\begin{abstract}
This study sought answers to the following question: How do teachers who teach mathematics in the Final Years of Elementary School, in the municipal network of Barreiras-BA, understand mathematical games as an instrument for the development of logical reasoning? This is a research with a qualitative approach of an exploratory type, which aimed to identify and to know the understanding of teachers who teach mathematics in the Final Years of elementary school, in the municipal network of Barreiras-BA, about mathematical games as an instrument for the development of logical reasoning. The data were produced using an exploratory questionnaire, with open and closed questions, and analyzed in the light of Bardin's Content Analysis. The research showed the
\end{abstract}




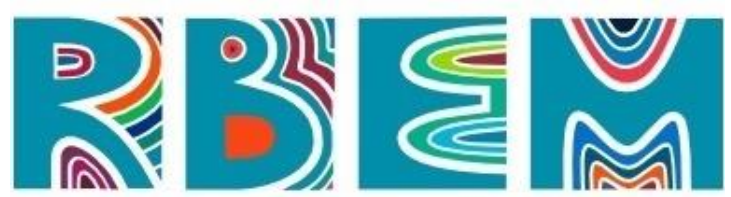

REVISTA BAIANA DE EDUCAÇÃO MATEMÁTICA

recognition by teachers of the game use as a resource that helps the development of logical reasoning, but some factors influence the (non) use of game as a resource capable of stimulating logical reasoning. They also highlight the conceptual difficulties as an "obstacle" for the advancement of logical reasoning. However, these professionals signal that they use the game in the context in which they operate.

Keywords: Teacher Understanding. Mathematics. Games. Logical reasoning.

\section{Comprensión de los profesores que enseñan matemáticas sobre la relación entre el juego y el razonamiento lógico}

Resumen: Este estudio buscó respuestas a la siguiente pregunta: ¿Cómo entienden los docentes que enseñan matemáticas en los últimos años de la Escuela Primaria, en la red municipal de Barreiras-BA, los juegos matemáticos como un instrumento para el desarrollo del razonamiento lógico? Se trata de una investigación con abordaje cualitativo de tipo exploratorio, que tuvo como objetivo identificar y comprender la comprensión de los docentes que imparten matemáticas en los últimos años de la escuela primaria, en la red municipal de Barreiras-BA, sobre los juegos matemáticos como instrumento para el desarrollo del razonamiento lógico. Los datos se elaboraron mediante un cuestionario exploratorio, con preguntas abiertas y cerradas, y se analizaron a la luz del Análisis de Contenido de Bardin. La investigación mostró el reconocimiento por parte de los docentes del uso del juego como un recurso que ayuda al desarrollo del razonamiento lógico, pero algunos factores influyen en el (no) uso del juego como recurso capaz de estimular el razonamiento lógico. También destacan las dificultades conceptuales como un "obstáculo" para el avance del razonamiento lógico. Sin embargo, estos profesionales señalan que utilizan el juego en el contexto en que operan.

Palabras clave: Comprensión del maestro. Matemáticas. Juegos. Razonamiento lógico.

\section{Introdução}

O uso do jogo na disciplina de Matemática, quando adequadamente planejado, é uma estratégia de ensino para a aprendizagem, e se apresenta como mais uma das possibilidades pedagógicas de como a Matemática e o uso de jogos podem andar juntos no estímulo do raciocínio lógico, pois busca entender os conceitos matemáticos de forma motivadora e dinâmica para o aluno, sendo "motivação" um dos fios condutores no processo de ensino e de aprendizagem, e ainda pode promover a interação e o prazer no processo de aprendizagem. Nesta pesquisa, é adotada a concepção de jogo na perspectiva de Kishimoto (2011, p. 107) ao afirmar que jogo é: "1. O resultado de um sistema linguístico que funciona dentro de um contexto social; 2. Um sistema de regras; e 3. Um objeto". Já a concepção de raciocínio lógico utilizada firma-se nas ideias de Copi (1978, p. 21), ao salientar que: “o raciocínio é um gênero especial de pensamento, no qual se realizam inferências ou se derivam conclusões a 


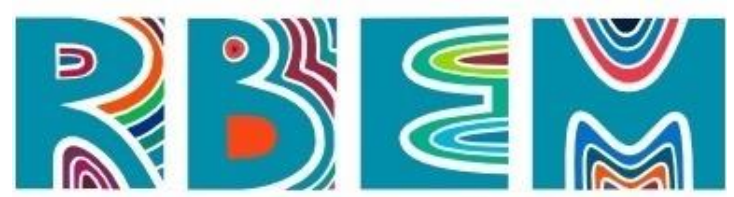

REVISTA BAIANA DE EDUCAÇÃO MATEMÁTICA

partir de premissas". Esses conceitos serão os conceitos serão aprofundados mais adiante no texto.

O interesse pelo objeto de pesquisa surgiu da experiência da primeira autora, no curso de Licenciatura em Matemática, mediante o cumprimento do componente curricular Laboratório do Ensino da Matemática, ocorrido no primeiro semestre de 2014. Nessa disciplina foram desenvolvidas atividades de leitura, discussão e produção de recursos didáticos cujo foco entrelaçava a integração dos jogos com o raciocínio lógico. Essa vivência fez despertar o interesse em pesquisar sobre o tema. Ao mesmo tempo em que foi selecionada para o Programa Institucional de Bolsa de Iniciação à Docência (PIBID), teve a oportunidade de vivenciar oficinas cujo objetivo era manipulação de jogos, o que reforçou ainda mais o interesse e a inquietação com tal objeto. Durante as oficinas, era perceptível o empenho e participação dos alunos nas atividades propostas, que, em sua essência, eram jogos matemáticos tais como: trilha, bingo, dentre outros.

A partir de então surgiu a seguinte inquietação: como professores que ensinam matemática nos Anos Finais do Ensino Fundamental, na rede municipal de Barreiras-BA, entendem os jogos matemáticos como instrumento de desenvolvimento do raciocínio lógico? Tendo por base essa indagação, definimos o seguinte objetivo de pesquisa: identificar e compreender o entendimento dos professores que ensinam matemática nos Anos Finais do Ensino Fundamental, na rede municipal de Barreiras-BA, sobre os jogos matemáticos como instrumento de desenvolvimento do raciocínio lógico.

Este artigo está organizado em seções, que foram compostas de modo a permitir uma melhor aproximação do leitor com a pesquisa realizada: i) na introdução, a temática e problemática que orientam este estudo; ii) uma breve fundamentação teórica sobre a relação entre jogo e raciocínio lógico; iii) a abordagem metodológica e os participantes da pesquisa; iv) a análise dos dados, onde apresentamos e analisamos os dados produzidos pelos participantes; e, por fim, iv) a apresentação de algumas considerações.

\section{Alguns entendimentos sobre jogos matemáticos e raciocínio lógico}

Propomos, aqui, concepções de alguns autores a respeito do raciocínio lógico. No que diz respeito à lógica, ao seu significado, Itacarambi (2013, p. 21) pontua que "A lógica (do 


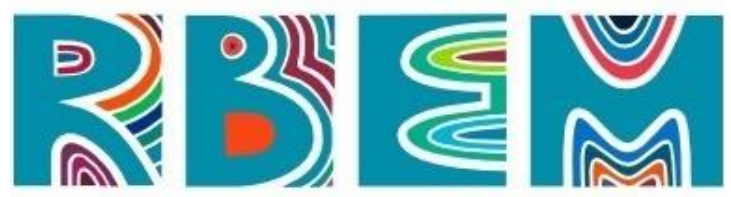

REVISTA BAIANA DE EDUCAÇÃO MATEMÁTICA

grego - logos) significa palavra, pensamentos, ideia, argumento, relato, razão, lógica, está relacionada à filosofia. [...] assim, a lógica é o ramo da filosofia que cuida dessas regras do bem pensar, sendo, portanto, um instrumento do pensar."

A autora enfatiza que a lógica está diretamente ligada ao pensamento em que há a necessidade do pensar e de utilizar o instrumento do pensar. Sobre isso, Delval (1998, p. 14) afirma que "a capacidade do pensar se desenvolve naturalmente quando se vive em um meio social adequado, e é necessária para essa vida em sociedade, já que para participar normalmente desse contexto é preciso pensar", isto é, o pensar é uma atividade inerente ao homem, que, de acordo com Delval (1998), o contexto pode ser um meio pelo qual esse pensar seja estimulado, reforçado e ressignificado em diferentes ambientes; no jogo, o pensar é tácito e pode constituir mais um meio pelo qual se reverbera a interlocução enquanto instrumento do pensar.

Ao se referir ao raciocínio lógico, Copi (1978, p. 20) destaca que:

A lógica tem sido frequentemente definida como a ciência das leis do pensamento. Mas essa definição, conquanto ofereça um indício sobre a natureza da lógica, não é exata. [...] a lógica não pode ser "a" ciência das leis do pensamento, porque a psicologia também é uma ciência que trata das leis mentais. E a lógica não é um ramo da psicologia: é um campo de estudo separado e distinto.

De acordo com o que pontua Copi (1978), a lógica é conhecida e já foi definida como a ciência que estuda as leis do pensamento, porém o autor se contradiz a essa definição, alegando ser a lógica uma ciência separada e distinta, por exemplo, da psicologia, que é uma ciência que trata das leis mentais. Copi (1978) considera a lógica como o ramo da ciência que estuda métodos para distinguir o raciocínio correto do incorreto.

Ainda de acordo Copi (1978, p. 20), "nem todo pensamento constitui um objeto de estudo para o lógico, todo raciocínio é pensamento, mas nem todo pensamento é raciocínio". Em seguida ele cita o exemplo de que é possível "pensar" em um número entre um a dez, como num jogo de sala, sem elaborar qualquer "raciocínio" sobre o mesmo. Isto é, ele designa o pensamento como uma situação como o exemplo supracitado, enquanto que o raciocínio exige a necessidade de questionar, a partir da situação de deduzir, refletir e raciocinar literalmente.

Dando continuidade à concepção de Copi (1978, p. 21) relativa ao raciocínio, ele afirma que "o raciocínio é um gênero especial de pensamento no qual se realizam inferências 


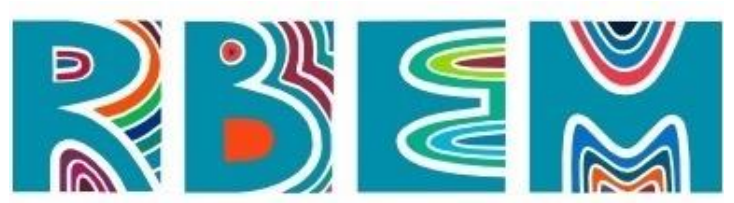

REVISTA BAIANA DE EDUCAÇÃO MATEMÁTICA

ou se derivam conclusões a partir de premissas". Essa é outra definição utilizada por muitos, conforme Copi, porém ainda não é essa a definição exata de raciocínio, pois ainda faz parte do material de estudo dos psicólogos.

Segundo Copi (1978, p. 21), “o lógico não está interessado, em absoluto, nos obscuros caminhos pelos quais a mente chega às suas conclusões durante os processos concretos de raciocínio"; vejamos o que pensa o autor sobre isso:

Ao lógico só interessa a correção do processo uma vez completado. Sua interrogação é sempre essa: a conclusão a que se chegou deriva das premissas usadas ou pressupostas? Se as premissas fornecem bases ou boas provas para a conclusão, se a afirmação da verdade das premissas garante a afirmação de que a conclusão também é verdadeira, então o raciocínio é correto. Do contrário, é incorreto. (COPI, 1978, p. 21).

Ainda conforme Copi (1978, p. 19), “o estudo da lógica é o estudo dos métodos e princípios usados para distinguir o raciocínio correto do incorreto". Em suma, a lógica é o ramo da ciência que estuda métodos para distinguir o raciocínio correto do incorreto.

Propomos aqui a possível relação entre o jogo matemático e o raciocínio lógico e os prováveis benefícios dessa articulação. De acordo com Dante (2003, p. 11-12), “é preciso desenvolver no aluno a habilidade de elaborar um raciocínio lógico e fazer uso inteligente e eficaz dos recursos disponíveis, para que ele possa propor boas soluções às questões que surgem em seu dia-a-dia, na escola ou fora dela”.

Dante (2003) faz referência à importância de desenvolver os conceitos matemáticos no cotidiano do aluno; segundo ele, essa atitude faz com que o aluno tenha uma visão positiva da Matemática, além de contribuir para o desenvolvimento do pensamento. Enfatiza, ainda, o uso de recursos durante esse processo; e o uso de jogos, enquanto metodologia, pode se caracterizar como um recurso acessível devido à possibilidade de construí-los com recursos de baixo custo.

Ao tratar da possibilidade de articulação entre jogo e raciocínio lógico, Muniz (2010) aborda que o jogo tem o papel, também, de comunicação entre a realidade interior e a realidade exterior, podendo, assim, construir capacidade criativa. O mencionado autor (2010, p. 131) destaca que "o lócus do jogo, no espaço da atividade matemática, estabelece os níveis de possibilidades e de limites de sua utilização da Educação Matemática”. Assim, podemos perceber, na escrita do autor, a relação do jogo com o raciocínio lógico, sendo que o jogo 


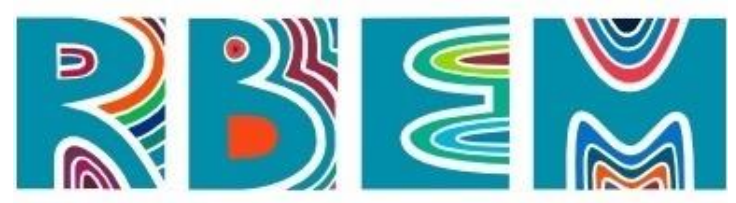

REVISTA BAIANA DE EDUCAÇÃO MATEMÁTICA

pode proporcionar a criatividade, que por sua vez se desenvolve por meio do raciocínio lógico, possibilitando um melhor entendimento, culminando na indispensável motivação para o aluno. Contudo, percebemos o jogo como um estímulo para ampliação do raciocínio lógico.

De acordo com Fiani (2009, p.12), “um jogo nada mais é do que uma representação formal que permite a análise das situações em que agentes interagem entre si, agindo racionalmente". Conforme sustenta o autor, o jogo proporciona ao jogador, por meio da interação, a habilidade de agir racionalmente, dessa forma, o jogo possui a capacidade de estímulo voltado ao desenvolvimento do raciocínio lógico.

Um jogo é um modelo formal e existem regras pré-estabelecidas para apresentar e estudar um jogo. Fiani (2009, p. 11-12) elenca algumas dessas regras.

Interações. Significam que as ações de cada agente, consideradas individualmente, afetam os demais. [...] situações de interação estratégica entre indivíduos podem ser consideradas como um jogo;

Agentes. Um agente é qualquer indivíduo, ou grupo de indivíduos, com capacidade de decisão para afetar os demais, um agente é denominado um jogador;

Racionalidade. Assumir que os agentes são racionais significa supor que os indivíduos empregam os meios mais adequados aos objetivos que almejam, sejam quais forem seus objetivos.

Como afirma Fiani (2009), o jogo é um modelo formal que possui regras e elenca algumas delas: na interação, a qual ele considera como um jogo, os indivíduos fazem escolhas e decisões frequentemente no meio social em que vivem. Por meio da interação e convívio com outras pessoas, os agentes, que o autor denomina de jogadores, têm o poder de decisão; e a racionalidade, que seria a estratégia ou os meios utilizados para atingir os objetivos do jogo.

Portanto, o autor acima referenciado, ao caracterizar o jogo como modelo formal, estabelece algumas regras que servirão para o aprimoramento do raciocínio lógico: interações, agentes e racionalidade, esta última é de extrema relevância para o desenvolvimento do raciocínio lógico, pois, para que este seja desenvolvido, é preciso que os agentes atuem de forma racional. Para entendermos um pouco mais de racionalidade, vejamos o que afirma Fiani $(2009$, p. 22) quando pontua que um agente racional é aquele que:

1. Aplica a lógica a premissas dadas para chegar às suas conclusões;

2. Considera apenas premissas justificadas a partir de argumentos racionais;

3. Usa evidências empíricas com imparcialidade ao julgar informações sobre fatos concretos. 


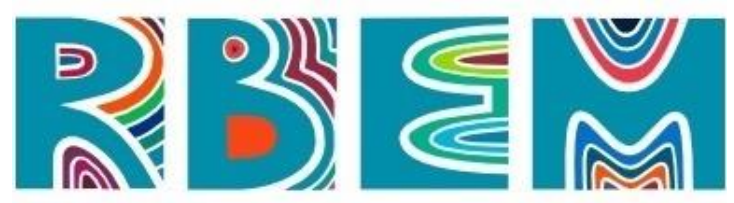

REVISTA BAIANA DE EDUCAÇÃO MATEMÁTICA

Segundo o autor, espera-se que o jogador raciocine logicamente, partindo de premissas de forma lógica, que as suas escolhas se baseiem nas premissas em que se apoia o raciocínio lógico e que as evidências sejam consideradas sem distorcer os fatos.

Atrelando jogos ao raciocínio lógico podemos obter resultados significativos, no que diz respeito ao ensino e à aprendizagem da disciplina Matemática. Sendo assim, trazemos ideias de alguns pesquisadores que destacam o uso de jogos como desenvolvimento do raciocínio lógico na Educação Matemática.

Segundo Marim e Barbosa (2010, p. 232-233), "educadores matemáticos devem procurar alternativas para aumentar a motivação, desenvolver a autoconfiança, o raciocínio lógico-dedutivo", portanto, os jogos podem ser utilizados como mediadores da aprendizagem para introduzir conceitos matemáticos, bem como para aprofundar os conteúdos já estudados, motivar os alunos e desenvolver o raciocínio lógico.

Sobre o jogo, os Parâmetros Curriculares Nacionais (BRASIL, 1997, p. 35) ressaltam que:

Além de ser um objeto sociocultural em que a matemática está presente, o jogo é uma atividade natural no desenvolvimento dos processos psicológicos básicos; supõe um "fazer sem obrigação externa e imposta", embora demande exigências, D) PUE REISTA normas e controle.

Conforme descrito, o jogo é um objeto em que a Matemática está presente; há que se considerar, então, a relevância desse objeto como instrumento sugestivo para inserção nas aulas de Matemática, por ser um objeto capaz de desenvolver os processos psicológicos, isto é, desenvolver o pensamento, as habilidades que contribuirão para o pensar e fazer matemático do aluno. Para tanto, é necessário atender as exigências estabelecidas, "fazer sem obrigação": na medida em que o objeto é imposto ele deixa de ser jogo, conforme abordam os PCNs e a Base Nacional Comum Curricular- BNCC; para que haja desenvolvimento de habilidades e do raciocínio lógico, é necessário que o aluno o pratique de forma espontânea sem estar sujeito ao jogo.

A utilização dos jogos representa conquista cognitiva, social e moral, além de um estímulo para o desenvolvimento do raciocínio lógico do aluno. Pois,

um aspecto relevante nos jogos é o desafio genuíno que eles provocam no aluno, que gera interesse e prazer. Por isso, é importante que os jogos façam parte da cultura escolar, cabendo ao professor analisar e avaliar a potencialidade educativa dos 


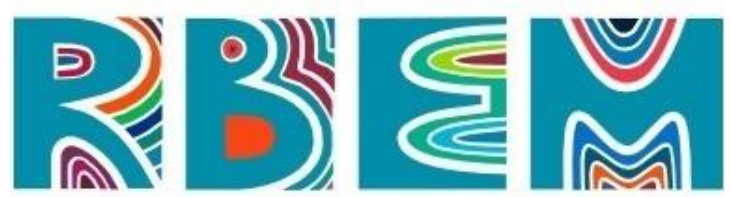

REVISTA BAIANA DE EDUCAÇÃO MATEMÁTICA

diferentes jogos e o aspecto curricular que se deseja desenvolver (BRASIL, 1997, p. 36)

O jogo por apresentar-se como objeto que propicia desafios, instiga no aluno o interesse e o desejo em querer praticá-lo; quando inserido como parte da cultura escolar, pode ser um recurso possível para desenvolver potencialidades além de estimular a busca pelo conhecimento.

\begin{abstract}
Desse modo, recursos didáticos como malhas quadriculadas, ábacos, jogos, livros, vídeos, calculadoras, planilhas eletrônicas e softwares de geometria dinâmica têm um papel essencial para a compreensão e utilização das noções matemáticas. Entretanto, esses materiais precisam estar integrados a situações que levem à reflexão e à sistematização, para que se inicie um processo de formalização (BRASIL, 2017, p. 276).
\end{abstract}

Ou seja, o jogo desempenha também um papel de concentração levando o aluno a pensar, o que é parte da Matemática, podendo desenvolver o raciocínio lógico matemático do aluno. O jogo e o raciocínio lógico matemático estão interligados, pois a Matemática é um componente que contribui para o desenvolvimento do raciocínio lógico.

Pires $(2009$, p. 18) assegura que "o processo-lógico matemático se trata de uma ação concreta em que há uma atividade mental e física do aluno". Portanto, podemos dizer que o processo-lógico matemático é um procedimento que envolve o pensamento; há uma atividade cerebral e física do aluno para chegar à solução de um determinado problema.

Ainda, de acordo com Pires (2009, p. 18), "a vida do aluno está baseada em um processo construtivo que tem como ponto de partida a motivação"; o aluno precisa de motivação e para isso os jogos que estimulam o raciocínio podem ser designados para tal função. Como já discutimos anteriormente, um dos recursos possíveis para a motivação é o jogo, por conter características que poderão propiciar o interesse do aluno, gerando, dessa forma, a motivação, sendo esta essencial para que o aluno tenha interesse em buscar aprimorar o conhecimento, já que "os jogos desafiam o pensamento dos alunos impulsionando novas descobertas" (PIRES, 2009, p. 22).

Então, se os jogos desafiam o pensamento e a lógica estuda o pensar, entendemos que os jogos podem desenvolver o raciocínio lógico. A capacidade de raciocinar logicamente irá permitir o desenvolvimento do pensamento e, nesse contexto, os jogos poderão ser úteis para impulsionar os alunos a estimular o raciocínio lógico, fomentando novas descobertas. Desse 


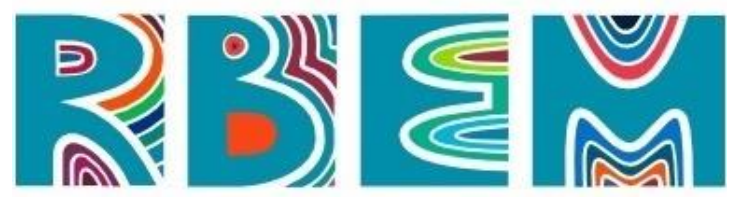

REVISTA BAIANA DE EDUCAÇÃO MATEMÁTICA

modo, conforme Pires (2009, p. 23), “os jogos são tidos como meios favoráveis e importantes para o trabalho pedagógico, eles representam formas interessantes de propor problemas aos alunos, por seu modo atrativo e, muitas vezes, pela criatividade ao elaborar as estratégias do jogo".

Os jogos, por serem desafiadores, desenvolvem a criatividade auxiliando no pensamento por soluções rápidas, criando estratégias mais eficazes para a solução de determinados problemas, o que desenvolve o cérebro ou o raciocínio lógico matemático. Pires (2009, p. 23) enfatiza que "todo esse exercício de desenvolver a criatividade dentro de um jogo auxilia no raciocínio lógico matemático dos alunos, que, ao procurarem por soluções rápidas e mais viáveis, aprimoram a atividade cerebral". Pires (2009) ressalta que as atividades/exercícios desenvolvidos com o auxílio do jogo podem contribuir não somente para o desenvolvimento do raciocínio lógico matemático dos alunos, como também estimulam a atividade cerebral dos mesmos - os jogos que desafiam o raciocínio lógico podem exercitar as funções do cérebro.

Outro motivo para a utilização de jogos nas aulas de Matemática, segundo Pires (2009, p. 24) é a "preparação de cidadãos conscientes e qualificados para os desafios do mundo"; os jogos matemáticos utilizados como ferramenta são capazes de desenvolver o raciocínio lógico, possibilitando a preparação do aluno não somente para a vida escolar, como também para a vida pessoal e profissional. Na próxima seção, apresentamos o cenário, os participantes da pesquisa e a abordagem metodológica.

\section{Cenário de pesquisa}

A pesquisa foi realizada em duas escolas públicas municipais da cidade de Barreiras $\mathrm{BA}$, as quais recebem alunos de toda região adjacente. As escolas ficam localizadas no centro da cidade, acolhendo alunos do $6^{\circ}$ ano ao $9^{\circ}$ ano do Ensino Fundamental, funcionando nos períodos matutino e vespertino.

Os critérios utilizados para a escolha dessas escolas foi que alguns professores utilizavam jogos em suas aulas, além do desempenho no Índice de Desenvolvimento da Educação Básica - IDEB, do ano de 2015. Assim, selecionamos duas escolas de rede Municipal de Ensino da cidade de Barreiras - BA que obtiveram maior nota no IDEB; as 


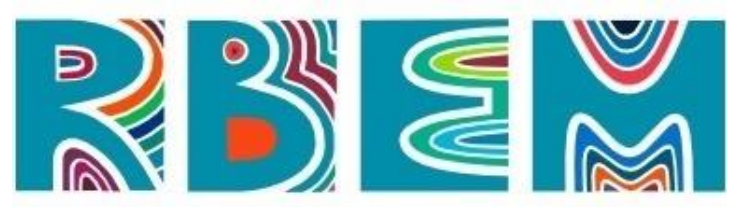

REVISTA BAIANA DE EDUCAÇÃO MATEMÁTICA

médias de desempenho utilizadas são obtidas por meio da Prova Brasil, para escolas e municípios e o do Sistema de Avaliação da Educação Básica (SAEB). Esses instrumentos de avaliação nacional fornecem dados que são utilizados para compor o IDEB, criado em 2007, para medir a qualidade de cada escola e de cada rede de ensino, segundo informações do INEP (2011).

\section{Participantes da pesquisa}

Neste trabalho, as escolas foram identificadas como escola A e escola B, e os professores com a letra $\mathrm{P}$ seguida de um algarismo na ordem crescente, com o intuito de proteger a identidade dos participantes da pesquisa. Vale ressaltar que só foram codificados os professores que devolveram o questionário. Na escola A trabalhavam quatro professores e na escola B oito professores, nas condições supracitadas; todos receberam o questionário, no entanto apenas sete responderam e devolveram o questionário, conforme quadro 1 a seguir.

\begin{tabular}{|l|c|c|l|}
\hline Escolas & $\begin{array}{l}\text { Quantitativo de } \\
\text { professores que ensinam } \\
\text { Matemática por escola }\end{array}$ & $\begin{array}{l}\text { Quantitativo de participantes } \\
\text { que responderam ao } \\
\text { questionário }\end{array}$ & $\begin{array}{l}\text { Professores e suas } \\
\text { respectivas identificações } \\
\text { no trabalho }\end{array}$ \\
\hline Escola A & 04 & 03 & P1; P2; P3 \\
\hline Escola B & 08 & 04 & P4; P5; P6; P7 \\
\hline Total & 12 & 7 & - \\
\hline
\end{tabular}

Quadro 1: Participantes da pesquisa (OS AUTORES).

Podemos perceber, ao observar o quadro 1 relativo à escola A, que apenas um professor não respondeu ao questionário alegando não ter tido tempo para responder. Já na escola B foram entregues oito questionários e recebemos apenas quatro, devido à resistência que os professores tiveram em responder: alguns alegaram não gostar da temática do trabalho se referir ao "jogo", outros disseram que a falta de tempo impossibilitou de contribuir para este trabalho não respondendo ao questionário, enquanto outros não fizeram justificativa para tal.

Método de pesquisa e procedimentos metodológicos 


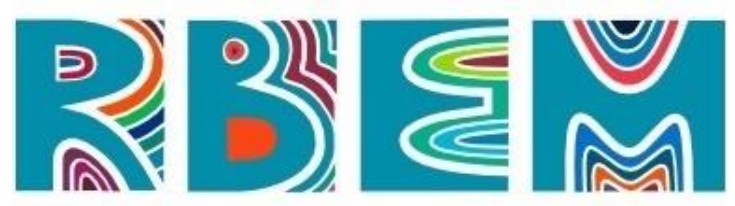

REVISTA BAIANA DE EDUCAÇÃO MATEMÁTICA

Trata-se de uma pesquisa qualitativa do tipo exploratória. Os dados para realização deste estudo foram produzidos por meio de questionário exploratório, composto por questões abertas e fechadas.

Na concepção de Marconi (1986, p. 74), “o questionário é um instrumento de coleta de dados, constituído por uma série ordenada de perguntas que devem ser respondidas por escrito e sem a presença do entrevistador", para que possamos compreender e verificar as concepções do sujeito sobre o tema a ser pesquisado.

O questionário exploratório foi aplicado com o professor que ensina matemática no Ensino Fundamental II, da rede municipal de ensino onde ocorreu a pesquisa. Após o questionário ser respondido pelos professores, pudemos analisar o que ele sinalizou sobre os entendimentos quanto aos jogos matemáticos e o raciocínio lógico.

Ressaltamos que foram respeitadas todas as normas e preceitos da ética na investigação proposta, a identidade ficou oculta e todas as informações fornecidas foram necessárias apenas para a classificação e análise dos dados. Para isso foi entregue, junto ao questionário exploratório, um termo de consentimento de participação, o qual deixava claro a não obrigatoriedade de participar da pesquisa, bem como a divulgação dos dados coletados, durante a pesquisa, exclusivamente para fins acadêmicos e científicos.

\section{Análise dos dados}

Após a tabulação, os questionários foram analisados. De acordo com Marconi (1986) “análise ou (explicação). É a tentativa de evidenciar as relações existentes entre o fenômeno estudado e outros fatores". Isto é, como o próprio nome diz, a análise tem a função de analisar os dados coletados para confirmar a pesquisa realizada.

Bardin (2007, p. 37) define Análise de Conteúdo como

Um conjunto de técnicas de análise das comunicações visando obter, por procedimentos sistemáticos e objetivos [sic] de descrição do conteúdo das mensagens, indicadores (quantitativos ou não) que permitam a inferência de conhecimentos relativos às condições de produção/recepção (variáveis inferidas) destas mensagens.

Desse modo, a Análise de Conteúdo consiste em um método de pesquisa utilizado para interpretar e descrever determinado conteúdo, conduzindo a descrições sistemáticas que 


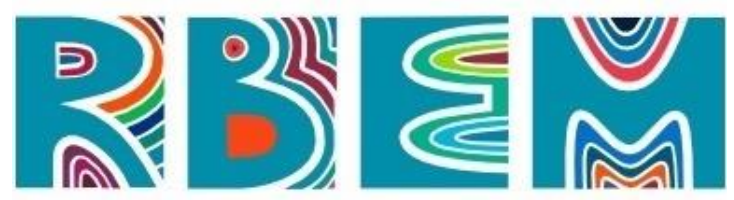

REVISTA BAIANA DE EDUCAÇÃO MATEMÁTICA

podem ser qualitativas ou quantitativas. Esse tipo de análise corrobora para descrever e sistematizar as falas descritas pelos professores questionados, de modo a obter uma análise crítica e aprofundada.

\section{Análises e resultados}

\section{Sobre o ensino da matemática nos Anos Finais do Ensino Fundamental: dificuldades e estratégias pontuadas pelos professores}

Abordaremos as questões que remetem ao ensino da matemática, relatadas pelos professores envolvidos na pesquisa, relacionadas às dificuldades recorrentes encontradas no processo de ensino e aprendizagem, as práticas metodológicas adotadas em suas aulas, o conceito de jogo e raciocínio lógico, dentre outros.

É perceptível, ao observarmos as respostas dadas pelos professores quando questionados sobre as dificuldades recorrentes encontradas em relação ao processo de ensino e de aprendizagem dos alunos, dificuldades semelhantes, muito embora sendo de turmas e anos diferentes, a maior dificuldade dos alunos citada é a falta de conhecimentos prévios.

Nas falas a seguir, temos ilustrada tal afirmação:

\footnotetext{
P1- Falta de conhecimentos prévios. [grifos nossos]

P3- Dificuldades nas quatro operações fundamentais e em interpretação de problema. [grifos nossos]

P4- Falta de base do Ensino Fundamental I. [grifos nossos]

P5- Falta de pré-requisito dos alunos. [grifos nossos]

P6- Falta de domínio das quatro operações. [grifos nossos]

P7- [...] sempre apresenta a falta de conhecimentos prévios. [grifos nossos] (QUESTIONÁRIO EXPLORATÓRIO)
}

Como podemos observar nos registros dos professores, a maior dificuldade que os alunos possuem com relação à Matemática é a falta de conhecimentos prévios, isso tem dificultado o ensino e, consequentemente, a aprendizagem dos alunos.

De acordo Ribeiro, Almeida e Gomes (2006, p.128),

o (in)sucesso dos alunos encontra-se influenciado, por exemplo, pela estrutura do currículo escolar, manuais escolares, métodos de avaliação, qualidade dos espaços e equipamentos escolares, formação e estabilidade do corpo docente, bem como a dimensão das escolas e das turmas. 


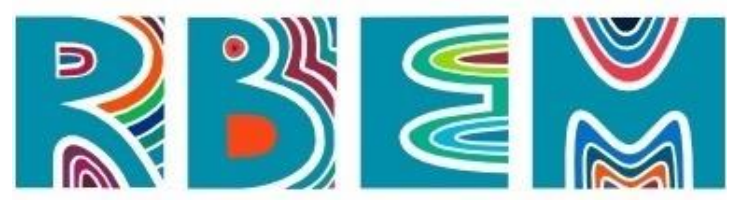

REVISTA BAIANA DE EDUCAÇÃO MATEMÁTICA

Podemos inquirir, portanto, que a falta de conhecimentos prévios dos alunos está relacionada a vários fatores, que vão desde a estrutura do currículo escolar à formação do professor, dentre outros. As condições estruturais da escola também favorecem a desmotivação tanto dos alunos quanto dos professores, isso condiciona o desinteresse e, consequentemente, a aprendizagem.

A falta desses conhecimentos prévios não é atribuída apenas aos fatores citados acima, mas, como destacam Ribeiro, Almeida e Gomes (2006, p. 129),

os processos e as estratégias que os alunos utilizam na sua apropriação dos conhecimentos, as suas percepções pessoais de competência e os seus discursos internos a propósito das tarefas a realizar ou dos seus motivos e metas, por exemplo, condicionam a sua aprendizagem e rendimento escolar.

Não basta apenas o professor, a escola e demais membros estarem envolvidos no processo de ensino e aprendizagem, é preciso que o aluno esteja interessado em querer aprender, ter metas e objetivos, pois isso irá levá-lo ao desejo de buscar e de aprender.

Mediante essas defasagens com relação aos conhecimentos prévios referentes à Matemática que os alunos possuem, procuramos identificar as estratégias de ensino que os professores questionados priorizam em suas aulas e que acreditam favorecer o processo de ensino e de aprendizagem da disciplina Matemática; a maior parte citou jogos, como, por exemplo: sudoku, trilha, bingo, dominó, entre outros. P3 acredita que "[...] utilizar alguns jogos; uso de textos do livro ou revistas. [grifos nossos]". P5 também acredita que a "[...] aplicação de jogos e desafios favorece o processo de ensino e aprendizagem dos alunos [grifos nossos]". P6 salienta que "[...] os jogos são ótimos para o desenvolvimento e a construção do conhecimento. [grifos nossos]”.

Logo, fica evidente a importância do uso de jogos como instrumento para construção do conhecimento matemático, parafraseando a fala de P3, P5 e P6 ao salientar que o jogo é uma estratégia de ensino.

Conforme ressalta Pires (2009) o uso de jogos pode ser favorável para o processo de ensino e de aprendizagem, tendo em vista as possibilidades que o jogo apresenta, por ser atrativo e desenvolver a criatividade. Partindo desse pressuposto, podemos inferir que o uso do jogo na sala de aula pode contribuir para o desenvolvimento da aprendizagem matemática 


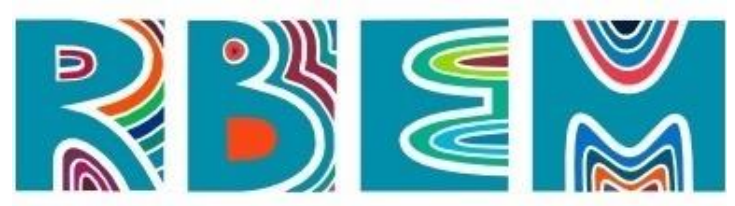

REVISTA BAIANA DE EDUCAÇÃO MATEMÁTICA

do aluno, uma vez que precisa de estratégias para solucionar os problemas e no jogo o aluno é conduzido a elaborar estratégias para atingir o objetivo.

Então, se os jogos desafiam o pensamento na busca pela solução, podemos afirmar que o uso dos jogos pode desenvolver conhecimentos e habilidades matemáticas, pois essa é uma área que depende do pensar, do raciocinar e o raciocínio lógico interfere de forma direta no desempenho de atividades matemáticas.

Conforme assinala Moura (1992) o jogo é um importante aliado do ensino quando utilizado como instrumento para o desenvolvimento da aprendizagem, podendo desenvolver habilidades, promovendo a aproximação do aluno também dos conteúdos culturais difundidos na escola.

Cabe salientar que o jogo é considerado como material de ensino quando avaliado como promotor da aprendizagem; dessa forma, o professor deverá ter senso crítico e reflexivo no uso dessa metodologia, discernindo se irá possibilitar ao aluno o conhecimento. Partindo deste objetivo maior que é o conhecimento, o professor poderá adotar algum instrumento para que seja utilizado como promotor da aprendizagem.

Com relação às práticas metodológicas adotadas nas aulas de Matemática, a maior parte dos pesquisados não abre mão de uma aula tradicional, como podemos ver nos extratos abaixo:

P1- Livro didático, quadro, pincel, caderno.

P2- Explanação oral dos conteúdos. [grifos nossos]

P3- Aula expositiva com o uso do livro didático; uso de texto de história da matemática. [grifos nossos]

P4- Jogos e brincadeiras. [grifos nossos]

P5- Aulas expositivas; pesquisas; estudo dirigido; exercício individual e/ou em grupo; utilização de jogos. [grifos nossos]

P6- Aulas expositivas; dialogadas; exercício de fixação; jogos; desafios com situações cotidianas, etc.

P7- Aula expositiva participada [...] jogos matemáticos, etc.

Existem diversas estratégias metodológicas que um professor pode utilizar para ministrar suas aulas, porém cada aula se diferencia na forma como é preparada e conduzida; a aula expositiva se destaca por ser considerada a mais comumente utilizada pelos professores. De acordo Lopes (1995, p. 38), “a literatura didática conceitua aula expositiva como uma comunicação verbal estruturada, utilizada pelos professores com o objetivo de transmitir 


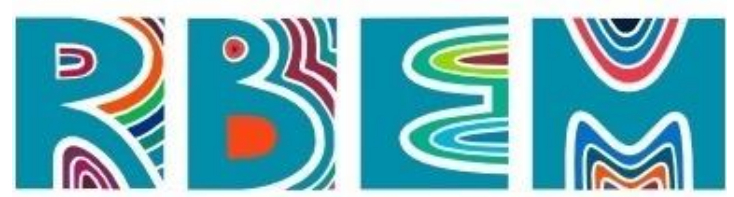

REVISTA BAIANA DE EDUCAÇÃO MATEMÁTICA

determinados conteúdos aos alunos". Ainda de acordo a autora citada, o professor deverá ter senso crítico ao planejar suas aulas de forma que atenda aos objetivos a que se propõe.

Embora essa técnica seja considerada predominantemente tradicional por muitos, Lopes (1995, p. 40) aponta algumas vantagens para essa técnica de ensino, dentre elas: economia de tempo, falta de bibliografia, alguns conteúdos não apresentam materiais disponíveis, entretanto se faz necessário o uso de aula expositiva, e a última vantagem é que a aula expositiva contribui para a compreensão de assuntos considerados complexos.

Apesar de muitos considerarem a prática tradicional de ensino ultrapassada, vale ressaltar que ela sempre esteve na prática docente e não deve ser rejeitada, mas pode ser transformada. De acordo Lopes (1995, p.42), “é possível transformar a aula expositiva numa técnica de ensino dinâmica e capaz de desenvolver o pensamento crítico do aluno". No entanto, é possível, sim, que a aula expositiva possa ser dinâmica e desenvolver a criatividade e o pensamento crítico do aluno, portanto vai depender da formação, criatividade e disposição do professor no uso dessas metodologias. P3 sinaliza um recurso interessante utilizado em suas aulas que é a história da matemática.

Para D’Ambrósio (2012, p. 27), “a história da matemática é um elemento fundamental para perceber como teorias e práticas matemáticas foram criadas, desenvolvidas e utilizadas num contexto específico de sua época". Este tipo de metodologia propicia mostrar que a Matemática tem um processo histórico, permitindo compreender o desenvolvimento da mesma; é interessante porque há uma interdisciplinaridade e contextualização e os alunos poderão ter maior aproximação e conhecimento de quem muito contribuiu para a história da Matemática, bem como entender como os conceitos matemáticos surgiram e se desenvolveram.

Uma técnica interessante utilizada por P6 é a aula expositiva dialogada. Na concepção de Lopes (1995, p.42), "uma alternativa para transformar a aula expositiva em técnica de ensino capaz de estimular o pensamento crítico do aluno é dar-lhe uma dimensão dialógica”, uma aula onde o aluno tem a liberdade de expressar e se questionar tem mais possibilidade de desenvolver o pensamento crítico e o conhecimento. Ainda, segundo Lopes (1995, p. 43), "na aula expositiva dialógica o professor toma como ponto de partida a experiência dos alunos relacionada com o assunto em estudo"; essa ideia valoriza os conhecimentos prévios que os 


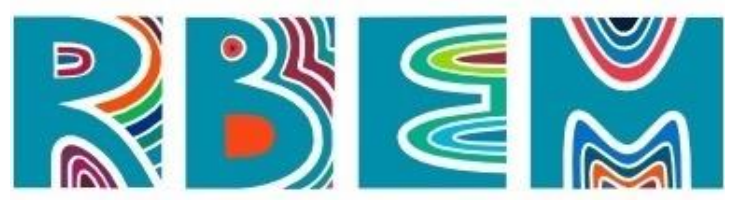

REVISTA BAIANA DE EDUCAÇÃO MATEMÁTICA

alunos possuem, dando a oportunidade de dialogarem, questionarem, podendo, dessa forma, estimularem o pensamento crítico.

A aula expositiva dialogada, conforme aponta Lopes (1995, p. 43), possibilita "estimular os alunos a levantar problemas e identificar as respectivas alternativas de solução; é uma atitude docente transformadora, pois esse tipo de exercício conjunto na sala de aula leva à reelaboração e produção de conhecimentos". Em outro momento, o autor argumenta: “é importante ressaltar que a aula expositiva é uma técnica de ensino semelhante às demais, apresentando vantagens e limitações, exigindo determinadas condições para ser bemsucedida"; o autor, também, salienta a importância da preparação do professor para a docência de qualidade, independentemente da técnica de ensino adotada (LOPES, 1995, p. 46).

Em geral, a aula expositiva tradicional, conforme Lopes (1995), apresenta respostas para o problema sem que haja um questionamento por parte dos alunos, e isso inibe o aluno de questionar, pois esse já recebe algo pronto; diferentemente da aula dialogada em que o aluno tem a capacidade de questionar e isso propicia troca de conhecimentos, incentivando os alunos a produzir e desenvolver novos conhecimentos. A seguir trazemos o que afirmam os professores que ensinam matemática sobre o seu pensar e fazer em relação aos jogos nas aulas de aula.

\section{Entendimento dos professores sobre a articulação entre jogo matemático e raciocínio lógico}

No quadro 2, a seguir, apresentamos o entendimento de professores sobre o conceito de raciocínio lógico, e quais atividades acreditam que contribuem para o desenvolvimento do raciocínio lógico matemático.

\begin{tabular}{|c|c|c|c|c|c|}
\hline Eixo & Sub-Eixo & Categorias & & olas & Fr* Total \\
\hline \multirow{9}{*}{ Raciocínio lógico } & \multirow{3}{*}{ Conceito } & & A & $\mathrm{B}$ & \multirow[b]{3}{*}{11} \\
\hline & & Capacidade de resolver problemas. & 02 & 01 & \\
\hline & & $\begin{array}{l}\text { Pensamento elaborado para chegar a } \\
\text { uma conclusão verdadeira ou falsa. }\end{array}$ & 02 & 06 & \\
\hline & \multirow{4}{*}{$\begin{array}{l}\text { Atividade que } \\
\text { estimula o } \\
\text { raciocínio lógico }\end{array}$} & Jogos (sudoku, bingo, trilha, etc.). & 01 & 04 & \multirow{4}{*}{11} \\
\hline & & Todas as atividades. & 01 & 02 & \\
\hline & & Situação-problema. & - & 01 & \\
\hline & & Desafios. & 01 & 02 & \\
\hline & \multirow{2}{*}{$\begin{array}{l}\text { Das atividades } \\
\text { realizadas quais }\end{array}$} & Jogos (sudoku, bingo, trilha, etc.). & 01 & 04 & \multirow{2}{*}{11} \\
\hline & & Todas as atividades. & 01 & 02 & \\
\hline
\end{tabular}




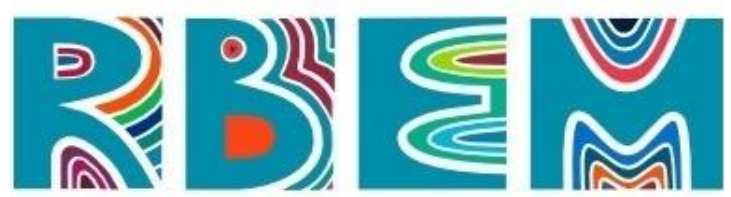

REVISTA BAIANA DE EDUCAÇÃO MATEMÁTICA

\begin{tabular}{|c|c|c|c|c|c|}
\hline & \multirow{2}{*}{$\begin{array}{l}\text { estimulam o } \\
\text { raciocínio lógico }\end{array}$} & Situação-problema. & - & 01 & \\
\hline & & Desafios. & - & 02 & \\
\hline & \multirow{4}{*}{$\begin{array}{l}\text { Articulação entre } \\
\text { jogo e raciocínio } \\
\text { lógico matemático }\end{array}$} & Estimula o raciocínio lógico. & 01 & 04 & \multirow{4}{*}{11} \\
\hline & & $\begin{array}{l}\text { Saber jogar e elaborar estratégias para } \\
\text { vencer. }\end{array}$ & 01 & 01 & \\
\hline & & $\begin{array}{l}\text { É uma maneira lúdica de promover o } \\
\text { aprendizado. }\end{array}$ & - & 01 & \\
\hline & & Conduz ao pensamento. & 02 & 01 & \\
\hline
\end{tabular}

Quadro 2: Entendimento de professores sobre o conceito de raciocínio lógico. Questionário aplicado nas escolas A e B com professores que ensinam matemática no Ensino Fundamental II (OS AUTORES). Nota: Fr* Frequência.

O raciocínio lógico é uma característica inerente ao ser humano, tendo em vista que este vive em uma sociedade onde há a necessidade do pensar, do raciocinar. Assim, exibimos, abaixo, as concepções dos professores questionados sobre raciocínio lógico.

P2- É a capacidade de resolver situações matemáticas de diferentes maneiras. [grifos nossos]

P3- É um pensamento elaborado para se chegar a uma conclusão falsa ou verdadeira. [grifos nossos]

P4- É o uso do pensamento formulando ideias refletindo, argumentando, ponderando para chegar a uma conclusão. [grifos nossos]

P6- Modo de pensar que ajuda a resolver um problema ou chegar a uma conclusão. [grifos nossos]. (QUESTIONÁRIO EXPLORATÓRIO).

O raciocínio lógico, como se pôde observar na citação acima, é visto de forma semelhante pelos pesquisados. A concepção de P3 partiu do conceito de preposição de lógica Matemática, que, de acordo com Alencar Filho (2002, p. 11), é o seguinte:

A lógica Matemática adota como regras fundamentais do pensamento os dois seguintes princípios (ou axiomas). (I) princípio da não contradição: uma proposição não pode ser verdadeira ou falsa ao mesmo tempo. (II) Princípio do terceiro excluído: toda a proposição ou é verdadeira ou é falsa, isto é, verifica-se sempre um destes casos e nunca um terceiro.

A citação acima remete ao conceito de lógica Matemática com relação à resposta do P3, ao explicitar sua visão de que a lógica é um pensamento elaborado para se chegar a uma inferência falsa ou verdadeira, estando esse tipo de informação na lógica Matemática escrita pelo autor supracitado. Apresentamos, a seguir, a opinião dos professores/as com relação aos tipos de atividades que acreditam estimular o raciocínio lógico matemático:

P1- Jogos matemáticos. [grifo nosso]

P2- Todas as atividades realizadas em sala de aula têm a capacidade de desenvolver o raciocínio lógico. [grifos nossos] 


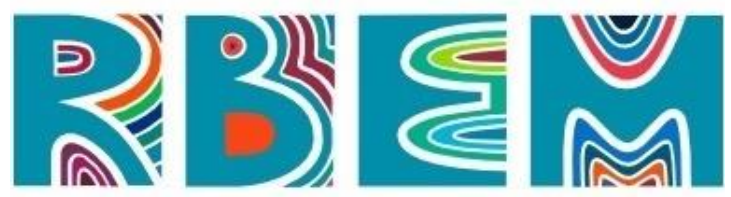

REVISTA BAIANA DE EDUCAÇÃO MATEMÁTICA

P5- Todas as atividades que levam o aluno à observação, à exploração e à concentração estimulam o raciocínio lógico, como, por exemplo, jogos, desafios, situações-problema, pois todas essas atividades requerem do aluno capacidade de organização do pensamento. [grifos nossos]

P6- Jogos como: sudoku, numerox, caça-dígito, trilhas, quebra-cabeças, dominó, baralho, desafios, etc. (QUESTIONÁRIO EXPLORATÓRIO).

Podemos observar nos relatos dados pelos professores que o uso do jogo matemático contribui de forma relevante no desenvolvimento de habilidades para elaborar o raciocínio lógico do aluno. O uso de jogos, como meio favorável para o processo de ensino e de aprendizagem, se baseia nas ideias de Pires (2009, p. 23), ao argumentar que "os jogos são tidos como meios favoráveis e importantes para o trabalho pedagógico, eles representam formas interessantes de propor problemas aos alunos, para seu modo atrativo e muitas vezes pela criatividade ao elaborar as estratégias do jogo". A autora apresenta o jogo como instrumento favorável para o processo de ensino e aprendizagem. De acordo com ela, o jogo representa formas atrativas de propor problemas aos alunos, propiciando o desenvolvimento de habilidades para elaborar estratégias, desenvolvendo, portanto, a criatividade. Abaixo, o entendimento dos professores/as sobre o jogo e sua articulação com o raciocínio lógico Matemático.

P2- O jogo estimula o raciocínio lógico porque conduz o aluno a pensar, pois o raciocínio lógico nada mais é do que o pensar. [grifos nossos]

P3- Saber como se joga e elaborar estratégia para vencer. [grifos nossos] $\mathrm{P} 4-$ Os jogos estimulam o raciocínio lógico matemático e aguçam os interesses dos educandos, facilitando sua aprendizagem e desmitificando que a matemática é para todos e não só para os mais talentosos. [grifos nosso]

P7- De modo geral, o jogo já é um instrumento que estimula o raciocínio lógico. Ele complementa na interpretação dos dados matemáticos que direcionam a solução. [grifos nossos]. (QUESTIONÁRIO EXPLORATÓRIO).

Os Parâmetros Curriculares Nacionais (BRASIL, 1997, p. 35) ressaltam a importância e a possível relação do jogo com o raciocínio lógico, como segue:

\begin{abstract}
Além de ser um objeto sociocultural em que a matemática está presente, o jogo é uma atividade natural no desenvolvimento dos processos psicológicos básicos; supõe um "fazer sem obrigação externa e imposta", embora demande exigências, normas e controle.
\end{abstract}

Desse modo, os PCNs e a BNCC trazem uma ideia do jogo como instrumento que poderá ser utilizado para desenvolvimento do raciocínio lógico do aluno. Porém, abordam características essenciais para que seja atingido o objetivo desejado: "fazer sem obrigação 


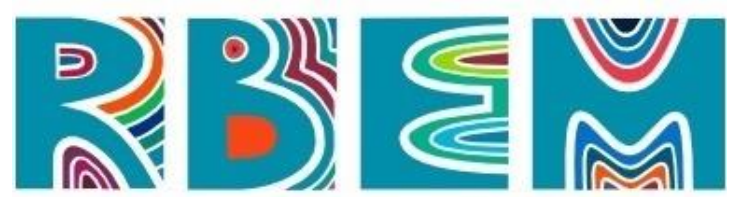

REVISTA BAIANA DE EDUCAÇÃO MATEMÁTICA

externa e imposta". Para que o jogo cumpra o papel de mediador do ensino e aprendizagem é necessário que seja realizado de forma livre e espontânea, sem, de forma alguma, o aluno estar submisso ao jogo, uma vez que isso aconteça, o jogo deixa de ser considerado mediador da aprendizagem e, mais especificamente, do desenvolvimento do raciocínio lógico.

É importante ressaltar que cabe ao professor analisar o jogo com o intuito de verificar se o mesmo está em conformidade com o conteúdo trabalhado e se pode contribuir para a aprendizagem dos conteúdos. E, ao fazer uso desta metodologia, o professor deverá promover ações que propiciem a troca de saberes, que o jogo não seja utilizado apenas como objeto de recreação, mas que sejam estabelecidos objetivos mediante os conteúdos que estão sendo trabalhados para obter resultados satisfatórios.

\section{Considerações finais}

O presente estudo se propôs a identificar e compreender o entendimento dos professores que ensinam matemática nos Anos Finais do Ensino Fundamental, na rede municipal de Barreiras-BA, sobre os jogos matemáticos como instrumento de

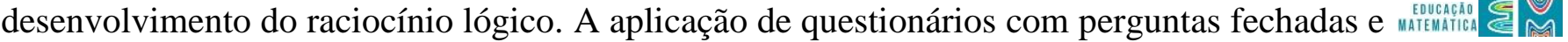
abertas foi um instrumento de produção de dados para conhecer a opinião dos sujeitos sobre o uso de jogos, bem como para obter informações pertinentes sobre eles e sobre como os mesmos têm impactado na aprendizagem dos estudantes.

Para tanto, realizamos a análise destacando as dificuldades recorrentes encontradas no processo de ensino e de aprendizagem, as práticas metodológicas adotadas nas aulas e o conceito de jogo e raciocínio lógico representado nos questionários.

Diante do que foi analisado nas respostas aos questionários exploratórios, os dados evidenciaram que os professores possuem entendimentos distintos sobre o conceito de jogo e sua articulação com o raciocínio lógico no ensino. Porém, abarcaram o mesmo foco que é o uso do jogo como instrumento para o desenvolvimento do raciocínio lógico.

Com base nos resultados da pesquisa, discutidos na seção anterior, inferimos que os professores apresentaram as concepções de jogo e raciocínio lógico cada um de forma singular, pois acreditam que o jogo pode ser uma ferramenta que contribui para o processo de ensino e aprendizagem de seus alunos. Porém, desafios como algumas dificuldades 


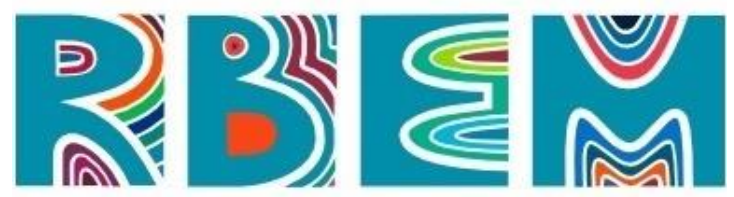

REVISTA BAIANA DE EDUCAÇÃO MATEMÁTICA

conceituais apresentadas pelos alunos, além da superlotação das salas de aula, têm dificultado o uso desta metodologia por parte dos professores que possuem uma visão positiva da Educação para a cidade de Barreiras-BA.

Levantar e analisar os dados oriundos da pesquisa com os sujeitos participantes sobre o trabalho desenvolvido ampliou a visão dos pesquisadores a respeito das suas práticas metodológicas e das possibilidades futuras, a partir do uso de jogos como instrumento para desenvolver o raciocínio logico.

Diante disso, esperamos que esta investigação contribua para que outras realidades compatíveis possam desenvolver práticas pedagógicas com o uso de jogos, para estimular e/ou aprimorar o raciocínio lógico. No entanto, podemos dizer que o estudo contribuiu ainda mais para a reflexão das próprias atividades planejadas e realizadas pelos pesquisadores. Nossas reflexões evidenciam a necessidade e reforçam o desejo de continuar estudando, visando ao constante aprendizado dos estudantes em diferentes níveis de ensino.

Como trabalhos futuros, a investigação sobre o uso dos jogos nos Anos Finais do Ensino Fundamental, bem como a estruturação de um banco de dados das respostas obtidas nos questionários para subsidiar outras pesquisas em continuidade a essa na escola estão sendo consideradas, podendo ser aplicados para professores que atuam na Educação Infantil.

\section{Referências}

ALENCAR FILHO, E. Iniciação à lógica matemática. São Paulo: Nobel, 2002.

BARDIN, L. Análise de conteúdo. Lisboa: Edições 70, 2007.

BRASIL. Secretaria de Educação Fundamental. Parâmetros Curriculares Nacionais: matemática. Brasília: MEC/SEF, 1997.

BRASIL. Instituto Nacional de Estudos e Pesquisas Educacionais Anísio Teixeira - INEP. IDEB 2011. Disponível em: http://portal.inep.gov.br/web/portal-ideb/o-que-e-o-ideb. Acesso em: 22 set. 2020.

BRASIL. Ministério da Educação. Base Nacional Comum Curricular - BNCC Versão Final. Brasília, DF, 2017.

COPI, I.M. Introdução à lógica. Tradução Álvaro Cabral. 2.ed. São Paulo: Mestre Jou, 1978.

D’AMBROSIO, U. Educação matemática da teoria à prática. Campinas, SP: Papirus, 2012. 


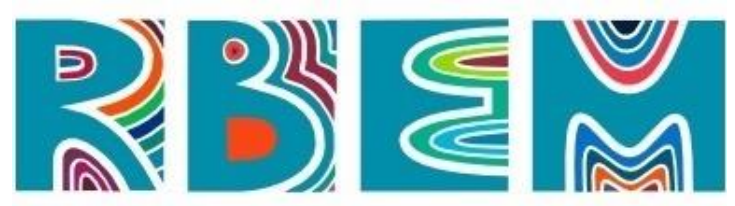

REVISTA BAIANA DE EDUCAÇĀO MATEMÁTICA

DANTE, L.R. Didática da resolução de problemas de matemática. 12.ed. São Paulo: Ática, 2003.

DELVAL, J. Aprender a aprender. Tradução Jonas Pereira dos Santos. Campinas, SP: Papirus, 1998.

FIANI, R. Teoria dos jogos. 3.ed. Rio de Janeiro: Elsevier, 2009.

ITACARAMBI, R.R. Jogo como recurso pedagógico para trabalhar matemática na escola básica: ensino fundamental. São Paulo: Livraria da Física, 2013.

KISHIMOTO, T.M. Jogo, brinquedo, brincadeira e a educação. 14.ed. São Paulo: Cortez, 2011.

LOPES, A. O. Aula expositiva: superando o tradicional. In: VEIGA, Ilma Passos Alencastro (Org.). Técnicas de ensino: por que não? 3.ed. Campinas, SP: Papirus, 1995.

MARCONI, M.A. Técnicas de pesquisa: planejamento e execução de pesquisas, amostragens e técnicas de pesquisa, elaboração, análise e interpretação de dados. São Paulo: Atlas, 1986.

MARIM. V.; BARBOSA, A.C.I. Jogos matemáticos: uma proposta para o ensino das operações elementares. In: OLIVEIRA. Cristiane Coppe. MARIM. Vlademir (Org.). Educação matemática: contextos e práticas docentes. Campinas, SP: Alínea, 2010.

MOURA, M.O. O jogo e a construção do conhecimento matemático. São Paulo: FDE, 1992. p. 45-52. (Série Ideias, n.10)

MUNIZ, C.A. Brincar e jogar: enlaces teóricos e metodológicos no campo da educação matemática. Belo Horizonte: Autêntica, 2010.

PIRES, K.A. O desenvolvimento do raciocínio lógico matemático por meio de jogos nas séries finais do ensino fundamental. Monografia. Jussara, GO: UEG, 2009.

RIBEIRO, I.S.; ALMEIDA, L.S.; GOMES, C. Conhecimentos prévios, sucesso escolar e trajetórias de aprendizagem: do $1^{\circ}$ para o $2^{\circ}$ ciclo do ensino básico. Avaliação Psicológica, v. 5, n. 2, p. 127-133, 2006.

Artigo submetido em: 02/12/2020

Artigo aceito em: 08/02/2021 